\title{
Palladium-catalysed direct arylation of heteroarenes using 1- (bromophenyl)-1,2,3-triazoles as aryl source
}

\author{
Halima Hadj Mokhtar, ${ }^{\mathrm{a}, \mathrm{b}}$ Nouria Laidaoui, ${ }^{\mathrm{a}, \mathrm{b}, \mathrm{c}}$ Douniazad El Abed, ${ }^{\mathrm{b} *}$ Jean-François Soulé, ${ }^{\mathrm{a} *}$ \\ Henri Doucet ${ }^{\mathrm{a} *}$
}

a Institut des Sciences Chimiques de Rennes, UMR 6226 CNRS-Université de Rennes "Organométalliques : Matériaux et Catalyse", Campus de Beaulieu, 35042 Rennes, France. Fax: (+33)2-23-23-63-84 E-mail: jean-francois.soule@univ-rennes1.fr; henri.doucet@univ-rennesl.fr.

${ }^{b}$ Laboratoire de Chimie Fine, Département de Chimie, Faculté des Sciences Exactes et Appliquées, Université d'Oran 1 Ahmed BenBella, BP. 1524, EL M'naouer Oran 31100 Algérie.

${ }^{c}$ Université des Sciences et de la Technologie d'Oran BP. 1505 El M'naouer Oran 31000 Algérie.

\begin{abstract}
A variety of 1-aryl-1,2,3-triazoles containing heteroarenes at C2-, C3- or C4-positions on the aryl ring was successfully prepared via palladium-catalysed direct arylation. These couplings were performed employing $1 \mathrm{~mol} \%$ of phosphine-free $\mathrm{Pd}(\mathrm{OAc})_{2}$ catalyst with 1-(bromophenyl)-1,2,3-triazoles and heteroarenes as coupling partners. A wide variety of heteroarenes such as thiazoles, thiophenes, furans, pyrroles or isoxazoles was tolerated.
\end{abstract}

Keywords: palladium, $\mathrm{C}-\mathrm{H}$ bond functionalization, heteroarenes, triazoles, aryl bromides

\section{Introduction}

1-Aryl-1,2,3-triazoles bearing heteroarenes on the phenyl ring are of considerable interest for pharmaceutical chemistry as they are employed as building blocks for access to biologically active compounds [1-5]. Therefore, the development of simple and convenient processes using readily accessible 1-aryl-1,2,3-triazole derivatives for the synthesis of such compounds is highly desirable.

Currently, heteroarylated 1-aryl-1,2,3-triazoles can be prepared by reaction of an azide functionalized benzene with a terminal alkyne in the presence of $\mathrm{CuSO}_{4}$ as catalyst [3,6,7] (Scheme 1, a), or via Pd-catalysed Suzuki coupling using a 4(bromophenyl)-1,2,3-triazole and benzofuran-2-ylboronic acid [8] (Scheme 1, b). An example of Ru-catalysed direct arylation using a 1-phenyl-1,2,3-triazole and a 5-bromofuran derivative as heteroaryl source has also been reported by Ackermann et al. [9] (Scheme 1, c). For this coupling reaction, the triazole moiety acts as a directing group to promote the arylation at C2-position of the phenyl ring. Therefore, this procedure is limited to the heteroarylations at C2-position of the phenyl unit of the 1-phenyl-1,2,3-triazole.

The Pd-catalysed direct arylation of several heteroaromatics [10-23], including triazoles [24-26] via a C-H bond activation, using aryl halides as aryl source has led to successes in recent years. Compared to classical Pd-catalysed reactions such as Suzuki, Stille, or Negishi couplings, [27,28] C-H bond functionalization reactions are very attractive, as they do not require the preliminary synthesis of organometallic derivatives. However, to our knowledge, so far no examples of metalcatalysed direct arylations of heteroarenes using 1-(bromophenyl)-1,2,3-triazoles as aryl sources have been described. Here, we wish to report on the access to a wide variety of 1-phenyl-1,2,3-triazoles bearing a heteroarene on the phenyl ring, using Pd-catalysed direct arylation reaction. 
a)<smiles>[R1]c1ccc(-c2cn(-c3ccc(-c4nc([R16])co4)cc3)nn2)cc1</smiles>

b)<smiles>CC(C)(C)C[C@H](OCc1cc2ccccc2o1)c1ccc2c(c1)CNCc1cnnn1-2</smiles><smiles>[R]c1c(C(=O)OCC)nnn1-c1ccc([GeH2])cc1</smiles>

Scheme 1. Synthesis of heteroarylated 1-aryl-1,2,3-triazoles.

\section{Results and discussion}

First, we prepared the bromo-substituted 1-aryl-1,2,3-triazoles 1-7 by reaction of bromophenyl azides with $\beta$-dicarbonyl compounds using a reported procedure (Scheme 2) [29].<smiles>[R]OC1CNCCO1</smiles><smiles>[R]c1c(C=C)nnn1-c1ccc(Cl)cc1</smiles>

Scheme 2. Preparation of the bromo-substituted 1-aryl-1,2,3-triazoles 1-7

Then, we examined the reaction of 2-ethyl-4-methylthiazole with ethyl 1-(4-bromophenyl)-5-methyl-1,2,3-triazole-4carboxylate 1 using our previously reported conditions for Pd-catalysed direct arylation of heteroarenes [30] (Table 1, entry 1). Starting form a slight excess of the thiazole derivative (1.5 eq.) with respect to the 1-phenyltriazole derivative 1, in the presence of $1 \mathrm{~mol} \% \mathrm{Pd}(\mathrm{OAc})_{2}$ as the catalyst, $\mathrm{KOAc}$ as the base, and DMA as the solvent at $150^{\circ} \mathrm{C}$, the desired product 8 was obtained in $91 \%$ yield. Under these reaction conditions, no decomposition of the triazole moiety was observed. The influence of a set of heteroarenes for reaction with 1 was then examined, under the same conditions (Table 1, entries 2-9). In the presence of thiophenes bearing methyl, acetyl or nitrile substituents at $\mathrm{C} 2$-position, the regioselective arylation at thienyl C5-position was observed affording 9-11 in 85-87\% yields. From furan derivatives bearing butyl or ester substituents at C2position, products $\mathbf{1 2}$ and $\mathbf{1 3}$ were obtained in $82 \%$ and $73 \%$ yields, respectively. A similar yield in $\mathbf{1 4}$ was obtained for the coupling of 1 with methyl 2-methylfuran-3-carboxylate (Table 1, entry 7). Both 1-methylpyrrole-2-carbaldehyde and 3,5dimethylisoxazole were also successfully coupled with 1 under the same reaction conditions, affording 15 and $\mathbf{1 6}$ in $77 \%$ and 92\% yields, respectively (Table 1, entries 8 and 9). Then, the influence the substituent at C5-position on the triazole was investigated. An ethyl C5-substituent on triazole instead of a methyl led to $\mathbf{1 7}$ in a similar yield (Table 1, entries 1 and 10). A phenyl C5-substituent was also tolerated. From 1-(4-bromophenyl)-5-phenyl-1,2,3-triazole-4-carboxylate 3 and 2-ethyl-4methylthiazole or 3,5-dimethylisoxazole the expected products $\mathbf{1 8}$ and $\mathbf{1 9}$ were obtained in high yields (Table 1, entries 11 and 12). 
Table 1. Palladium-catalysed direct arylation of heteroarenes with 1-(4-bromophenyl)-1,2,3-triazoles.
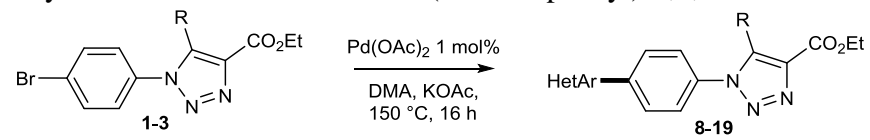

HetArH

\begin{tabular}{|c|c|c|c|}
\hline Entry & HetArH & Product & Yield (\%) \\
\hline 1 & & & 91 \\
\hline 2 & & & 87 \\
\hline 3 & & & 85 \\
\hline 4 & & & 87 \\
\hline 5 & & & 82 \\
\hline 6 & & & 73 \\
\hline 7 & & & 83 \\
\hline 8 & & & 77 \\
\hline 9 & & & 92 \\
\hline 10 & & & 90 \\
\hline 11 & & & 85 \\
\hline 12 & & & 83 \\
\hline
\end{tabular}

Conditions: $\mathrm{Pd}(\mathrm{OAc})_{2}(0.01 \mathrm{mmol})$, heteroarenes (1.5 mmol), 1-(4-bromophenyl)-1,2,3-triazoles 1-3 (1 mmol), KOAc (2 mmol), DMA, $150^{\circ} \mathrm{C}, 16 \mathrm{~h}$.

Then, the reactivity of 1-(3-bromophenyl)-1,2,3-triazole 4 in direct arylation of heteroarenes was examined (Table 2). Again, the use of $1 \mathrm{~mol} \% \mathrm{Pd}(\mathrm{OAc})_{2}$ catalyst in the presence of KOAc efficiently promotes the formation of products 20-22 in 81 92\% yields from 2-ethyl-4-methylthiazole, 2-methylthiophene and 2,4-dimethylisoxazole. Again, a phenyl substituent at C5- 
position of the triazole unit had no influence on the reaction, as from $\mathbf{5}$ and 2-ethyl-4-methylthiazole, product $\mathbf{2 3}$ was obtained in 94\% yield (Table 2, entry 4). Some of these structures might be employed as pincer ligands in the synthesis of iridium or platinum complexes with luminescence properties [31,32].

Table 2. Palladium-catalysed direct arylation of heteroarenes with 1-(3-bromophenyl)-1,2,3-triazoles.

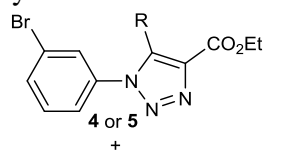

HetArH

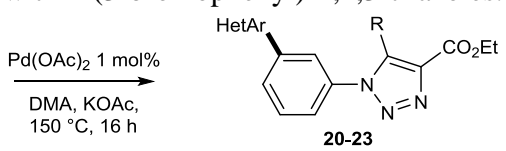

20-23

Entry

Conditions: $\mathrm{Pd}(\mathrm{OAc})_{2}(0.01 \mathrm{mmol})$, heteroarenes (1.5 mmol), 1-(3-bromophenyl)-1,2,3-triazoles 4 or 5 (1 mmol), KOAc (2 mmol), DMA, $150^{\circ} \mathrm{C}, 16 \mathrm{~h}$.

ortho-Substituents on aryl bromides generally exhibit an important effect on the reaction rates of palladium-catalysed reactions due to their steric and/or coordination properties. However, no poisoning of the palladium catalyst by coordination of 1-(2-bromophenyl)-1,2,3-triazole $\mathbf{6}$ was observed, and very good yields in $\mathbf{2 4}$ and $\mathbf{2 5}$ were obtained for the reaction of $\mathbf{6}$ with 2-ethyl-4-methylthiazole or 2-methylthiophene (Scheme 3).

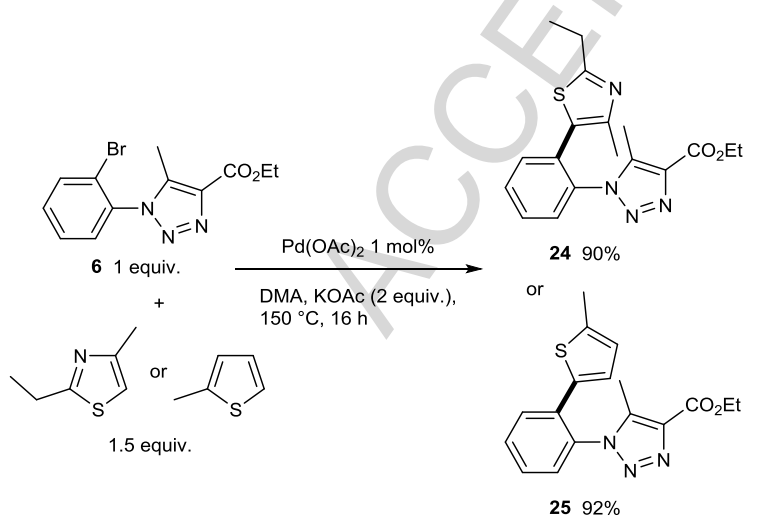

Scheme 3. Palladium-catalysed direct arylation of heteroarenes with 1-(2-bromophenyl)-1,2,3-triazole 6.

In 2014, the triazolophenanthridine derivative 26 of scheme 3 has been prepared in $35 \%$ yield by Huang, Wen et al. by $\mathrm{Cu}(\mathrm{I})$ catalysed cascade reaction of a cyclic diaryliodonium, sodium azide, and ethyl propiolate [33]. From the 1-(2-bromophenyl)1,2,3-triazole 7, an intramolecular direct arylation should give access to this triazolophenanthridine derivative. Our first attempt using $1 \mathrm{~mol} \% \mathrm{Pd}(\mathrm{OAc})_{2}$ catalyst only afforded the target product $\mathbf{2 6}$ in a low yield due to partial conversion of $\mathbf{7}$. On the other hand, the use of the more thermally stable $\mathrm{PdCl}\left(\mathrm{C}_{3} \mathrm{H}_{5}\right)(\mathrm{dppb})$ catalyst [34] gave 26 in $85 \%$ yield with a complete 
conversion of 7.
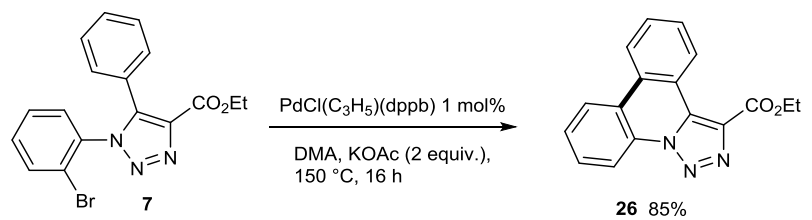

Scheme 4. Palladium-catalysed intramolecular direct arylation of 1-(2-bromophenyl)-5-phenyl-1,2,3-triazole 7.

In summary, we have demonstrated that using as little as $1 \mathrm{~mol} \%$ of $\mathrm{Pd}(\mathrm{OAc})_{2}$ as the catalyst precursor, 2-, 3-, or 4(bromophenyl)-1,2,3-triazoles can be heteroarylated on the phenyl ring, via a C-H bond activation of heteroarenes, to afford in high yields benzene rings bearing a triazole unit and also an other heteroarene unit. In all cases, no decomposition of the triazole motif was detected and no poisoning of the palladium catalyst was observed. Moreover, several heteroarenes such as furans, thiophenes, pyrroles, thiazoles or isoxazoles were tolerated. This phosphine-free catalyst procedure is economically and environmentally attractive, as 1) there is no need to eliminate phosphine derivatives at the end of the reaction, 2) with this $\mathrm{C}-\mathrm{H}$ bond activation procedure, no preparation of an organometallic derivative is required, reducing the number of steps and therefore the mass of waste products, 3) the major waste of theses couplings is the relatively non-toxic $\mathrm{AcOH} / \mathrm{KBr}$ instead of metallic salts with more classical metal-catalysed coupling reactions. For these reasons, this methodology is very promising for the sustainable synthesis of heteroarylated phenyl-1,2,3-triazoles. By contrast, for intramolecular arylation to prepare triazolophenanthridines, $\operatorname{PdCl}\left(\mathrm{C}_{3} \mathrm{H}_{5}\right)(\mathrm{dppb})$ catalyst should be preferred.

\section{Experimental}

\section{General procedure for the synthesis of 8-26:}

The reaction of the triazole-substituted aryl bromide $(1 \mathrm{mmol})$, heteroarene $(1.5 \mathrm{mmol})$ and $\mathrm{KOAc}(0.196 \mathrm{~g}, 2 \mathrm{mmol})$ at $150^{\circ} \mathrm{C}$ during $16 \mathrm{~h}$ in DMA ( $4 \mathrm{~mL})$ in the presence of $\mathrm{Pd}(\mathrm{OAc})_{2}(2.24 \mathrm{mg}, 0.01 \mathrm{mmol})$ or $\mathrm{PdCl}\left(\mathrm{C}_{3} \mathrm{H}_{5}\right)(\mathrm{dppb})(6.1 \mathrm{mg}, 0.01 \mathrm{mmol})$ (see table or schemes) under argon affords the coupling product after evaporation of the solvent and purification on silica gel. For procedures and NMR data, see electronic supplementary information.

\section{References}

[1] X. Sun, J. Qiu, S. A. Strong, L. S. Green, J. W. F. Wasley, J. P. Blonder, D. B. Colagiovanni, S. C. Mutka, A. M. Stout, J. P. Richards, G. J. Rosenthal Bioorg. Med. Chem. Lett. 21 (2011) 5849-5853.

[2] N. Boechat, V. F. Ferreira, S. B. Ferreira, M. de L. G. Ferreira, F. de C. da Silva, M. M. Bastos, M. dos S. Costa, M. C. S. Lourenco, A. C. Pinto, A. U. Krettli, A. C. Aguiar, B. M. Teixeira, N. V. da Silva, P. R. Martins, F. A. Bezerra, A. L. Camilo, G. P. da Silva, C. C. Costa, J. Med. Chem. 54 (2011) 5988-5999.

[3] J. Shi, L. Zhou, F. Amblard, D. R. Bobeck, H. Zhang, P. Liu, L. Bondada, T. R. McBrayer, P. M. Tharnish, T. Whitaker, S. J. Coats, R. F. Schinazi, Bioorg. Med. Chem. Lett. 22 (2012), 3488-3491.

[4] K. J. Harkala, L. Eppakayala, T. C. Maringanti, Org. Med. Chem. Lett. 4 (2014) 1-4.

[5] S.-W. Yang, J. Pan, C. Yang, M. Labroli, W. Pan, J. Caldwell, S. Ha, S. Koseoglu, J. C. Xiao, T. Mayhood, P. R. Sheth, C. G. Garlisi, J. WU, S. H. Lee, H. Wang, C. M. Tan, T. Roemer, J. Su, Bioorg. Med. Chem. Lett. 26 (2016) 4743-4747.

[6] D. J. Ritson, J. E. Moses, Tetrahedron 68 (2012), 197-203.

[7] C. Friebe, B. Schulze, H. Goerls, M. Jaeger, U. S. Schubert, Chem. Eur. J. 20 (2014) 2357-2366.

[8] J. R. Donald, R. R. Wood, S. F. Martin, ACS Comb. Sci. 14 (2012) 135-143.

[9] L. Ackermann, R. Vicente, A. Althammer, Org. Lett. 10 (2008) 2299-2302.

[10] N. Nakamura, Y. Tajima, K. Sakai, Heterocycles 17 (1982) 235-245.

[11] Y. Akita, A. Ohta, Heterocycles 19 (1982) 329-331.

[12] A. Ohta, Y. Akita, T. Ohkuwa, M. Chiba, R. Fukunaga, A. Miyafuji, T. Nakata, N. Tani, Y. Aoyagi, Heterocycles 31 (1990) 1951-1958.

[13] B.-J. Li, S.-D. Yang, Z.-J. Shi, Synlett (2008) 949-957.

[14] F. Bellina, R. Rossi, Tetrahedron 65 (2009) 10269-10310.

[15] X. Chen, K.M. Engle, D.H. Wang, J.Q. Yu, Angew. Chem., Int. Ed. Engl., 48 (2009) 5094-5115.

[16] L. Ackermann, R. Vincente, A. R. Kapdi, Angew. Chem. Int. Ed. 48 (2009) 9792-9826.

[17] J. Wencel-Delord, F. Glorius, Nature Chem. 5 (2013) 369-375. 
[18] I. Kuzhushkov, H. K. Potukuchi, L. Ackermann, Catal. Sci. Technol. 3 (2013) 562-571.

[19] R. Rossi, F. Bellina, M. Lessi, C. Manzini, Adv. Synth. Catal. 356 (2014) 17-117.

[20] C. B. Bheeter, L. Chen, J.-F. Soulé, H. Doucet, Catal. Sci. Technol. 6 (2016) 2005-2049.

[21] L. Theveau, C. Schneider, C. Fruit, C. Hoarau, ChemCatChem 8 (2016) 3183-3194.

[22] R. Rossi, M. Lessi, C. Manzini, G. Marianetti, F. Bellina, Tetrahedron 72 (2016) 1795-1837.

[23] P. H. Dixneuf, H. Doucet, C H Bond Activation and Catalytic Functionalization II, Springer, Heidelberg, 2016

[24] M. Iwasaki, H. Yorimitsu, K. Oshima, Chem. Asian J. 25 (2007) 1430-1435.

[25] L. Ackermann, R. Vicente, R. Born, Adv. Synth. Catal. 350 (2008) 741-748.

[26] L. Ackermann, A. Althammer, S. Fenner, Angew. Chem. Int. Ed. 48 (2009) 201-204.

[27] J. J. Li, G. W. Gribble, Palladium in Heterocyclic Chemistry, Pergamon: Amsterdam, 2000.

[28] L. Ackermann, Modern arylation methods, Eds.: Wiley Online Library, 2009.

[29] R. Fusco, G. Bianchetti, D. Pocar, R. Ugo, Renato, Gazz. Chim. Ital. 92 (1962) 1040-1061.

[30] J. Roger, H. Doucet, Tetrahedron 65 (2009) 9772-9781.

[31] J. Kuwabara, T. Namekawa, M.-a. Haga, T. Kanbara, Dalton Trans. 41 (2012) 44-46.

[32] K. Okamoto, T. Kanbara, T. Yamamoto, A. Wada, Organometallics 25 (2006) 4026-4029.

[33] Z. Liu, D. Zhu, B. Luo, N. Zhang, Q. Liu, Y. Hu, R. Pi, P. Huang, S. Wen, Org. Lett. 16 (2014), 5600-5603.

[34] T. Cantat, E. Génin, C. Giroud, G. Meyer, A. Jutand, J. Organomet. Chem. 687 (2003) 365-376.

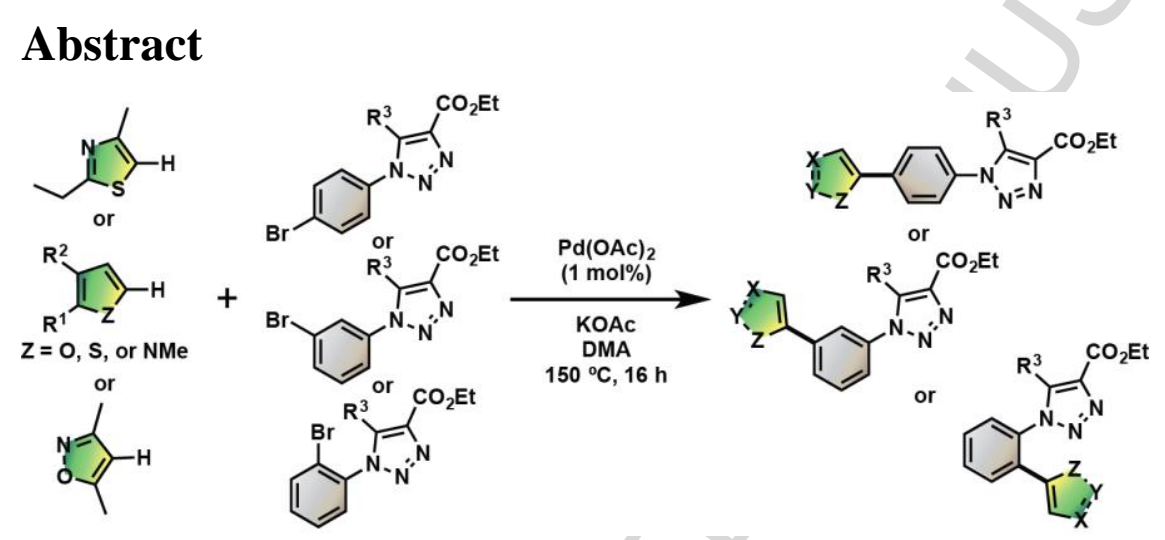

